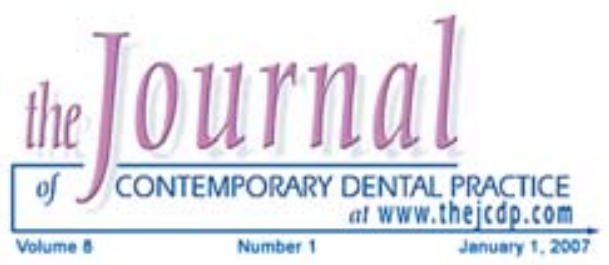

\title{
Marginal and Internal Adaptation of Commercially Pure Titanium and Titanium- Aluminum-Vanadium Alloy Cast Restorations
}

\section{Khalid A. Al Wazzan, BDS, MS; Ahmad A. Al-Nazzawi, BDS}

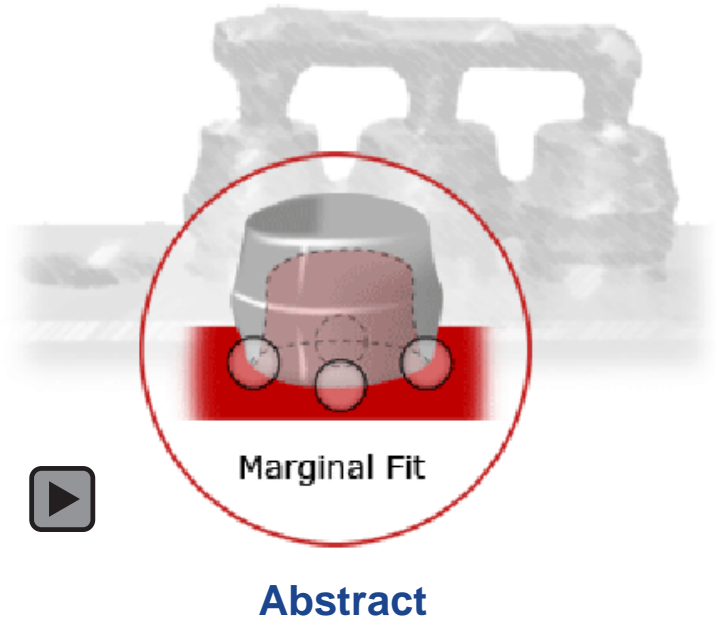

Aim: The purpose of this in vitro study was to investigate the marginal accuracy and internal fit of complete cast crowns and three-unit fixed partial dentures (FPDs) cast with commercially pure titanium (CPTi) and TitaniumAluminum-Vanadium alloy (Ti-6Al-4V).

Methods and Materials: CPTi and Ti-6Al-4V alloy were used to cast twelve single crowns and twelve three-unit FPDs. A traveling microscope was used to measure marginal gap and discrepancies in internal fit. Two and oneway analysis of variance (ANOVA) analyses were used to determine the effects of the marginal and internal fit discrepancies.

Results: The Ti-6Al-4V alloy demonstrated a significantly smaller marginal gap than CPTi $(\mathrm{P}<0.0001)$. The recorded marginal discrepancies for both metals were within a clinically accepted range $(<100 \mu \mathrm{m})$. The single crown fit discrepancy was significantly smaller than the three-unit FPD for both the CPTi and the Ti-6Al-4V alloy $(P<0.0001)$. For the internal fit discrepancy, the occlusal surface showed the greatest gaps.

Conclusions: The Ti-6AI-4V alloy demonstrated a better fit than CPTi. Single crowns showed an improved fit when compared with the three-unit FPD. Mid-occlusal internal gap demonstrated greater values than the axial internal gap.

Clinical Implications: This in vitro study suggested marginal fit of complete crowns and three-unit FPDs cast by $\mathrm{CPTi}$ or Ti-6Al-4V alloy were within the range of what is clinically acceptable for longevity of restorations.

(C) Seer Publishing 
Keywords: Marginal accuracy, fit discrepancy, titanium, titanium alloys, casting

Citation: Al Wazzan KA, Al-Nazzawi AA. Marginal and Internal Adaptation of Commercially Pure Titanium and Titanium-Aluminum-Vanadium Alloy Cast Restorations. J Contemp Dent Pract 2007 January;(8)1:019-026.

\section{Introduction}

Until the 1970s, only gold-based alloys were used to fabricate cast restorations. For economic reasons, several alternative casting alloys were progressively developed to replace high gold alloys. Recently, titanium (Ti) and its alloys have become a material of great interest in dentistry and have been used increasingly for the construction of metal-ceramic restorations. ${ }^{5}$ One of the early techniques used to fabricate $\mathrm{Ti}$ restorations was the development of Ti machining as a substitute for the time-honored lost-wax casting technique. ${ }^{2}$ The dramatic improvement in Ti casting technology and the preference for Ti prosthetic superstructures for dental implants expands its use in clinical prosthodontics.

It appears $\mathrm{Ti}$ is a possible economical and biocompatible alternative for existing conventional alloys. The most attractive property of $\mathrm{Ti}$ is its superior biocompatibility. ${ }^{1,3-5}$ However, there are several other desirable mechanical properties of $\mathrm{Ti}$ including its light weight, strength-to-weight ratio, high ductility, and low thermal conductivity. Theoretically, these mechanical properties would permit design modifications in Ti restorations resulting in more functional and comfortable use. ${ }^{1}$ In addition, the low density of Ti allows routine dental $\mathrm{X}$-rays to pass through $\mathrm{Ti}$ crowns or frameworks which may help with a clinical diagnosis. ${ }^{5}$

Commercially pure titanium (CPTi) has been reported to have low strength, poor wear resistance, and is difficult to polish. ${ }^{6,7}$ As a result, several $\mathrm{Ti}$ alloys have been formulated for biomechanical applications such as dental restorations. Ti can be alloyed with various elements primarily to improve mechanical properties such as strength, high temperature performance, creep resistance, weldability, and formability. ${ }^{8,9}$ Among the various Ti alloys, the Titanium-Aluminum-Vanadium alloy (Ti6Al4V) was FDA-approved and is one of the most popular Ti alloys used in dentistry. ${ }^{1,9}$ Ti6Al4V alloy showed greater bending strength and hardness than $\mathrm{CPTi}^{10}$ and has a lower melting point. ${ }^{9}$
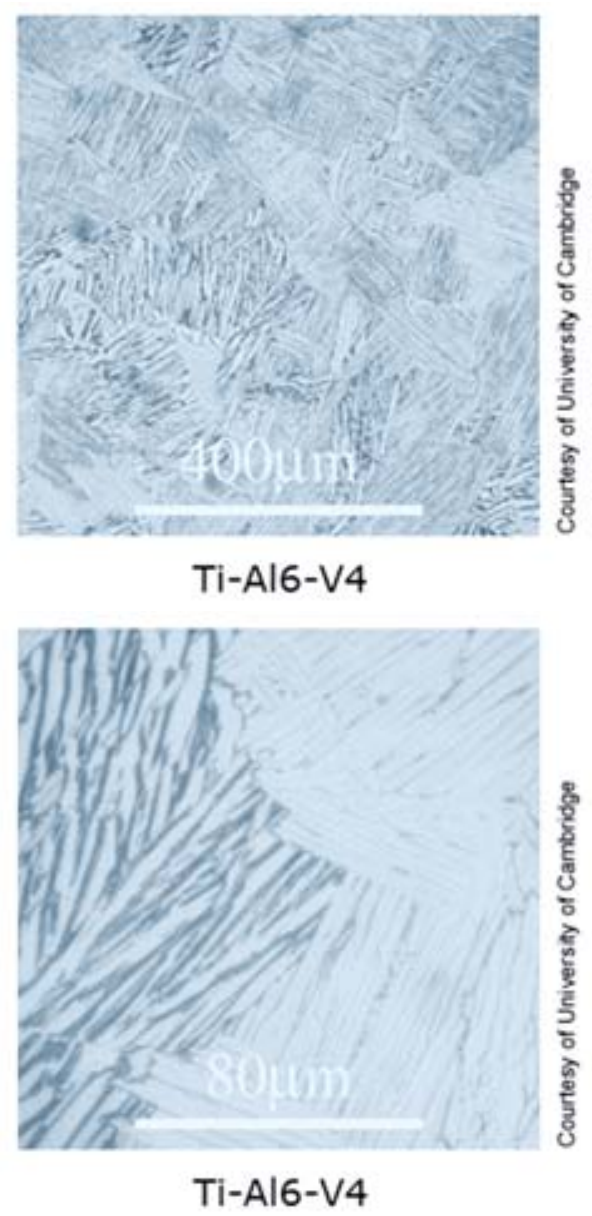

Marginal accuracy is considered a crucial factor in the success and longevity of a cast restoration. Ideally, cemented cast restoration margins should precisely meet the finish line of prepared teeth with non-detectable junctions. In reality, clinical perfection is difficult to achieve and difficult to verify. Dedmon, ${ }^{11}$ in an in vitro study using a stainless-steel device, reported minimal marginal openings deemed acceptable by a group of prosthodontists averaged 114 and $93 \mu \mathrm{m}$. McLean and Von Frauhofer ${ }^{12}$ stated inaccuracies of fit of $100 \mu \mathrm{m}$ were normal and discrepancies less than $80 \mu \mathrm{m}$ were difficult to detect under clinical conditions. However, Kashani et al. ${ }^{13}$ considered discrepancies exceeding $100 \mu \mathrm{m}$ as an unacceptable marginal opening. Moreover, 
Blackman et al. ${ }^{14}$ reported a small marginal gap (approximately $50 \mu \mathrm{m}$ ) might be acceptable.

Even though early attempts were not encouraging, ${ }^{15,16}$ subsequent studies reported clinically acceptable marginal gaps for cast CPTi crowns. ${ }^{14,17-19}$ Blackman et al. ${ }^{14}$ examined the fit of full crown Ti castings of maxillary central incisors and premolars with 45- and 90-degree margins fabricated using an indirect technique. They recorded approximately $50 \mu \mathrm{m}$ mean marginal gaps for both 45- and 90-degree margins. Leong et al. ${ }^{17}$ found mean marginal gaps of cast $\mathrm{Ti}$ crowns to be $60 \mu \mathrm{m}$. Oruc and Tulunoglu ${ }^{18}$ results revealed mean marginal gaps of $51 \mu \mathrm{m}$ prior to application of ceramic materials and $58 \mu \mathrm{m}$ after ceramic application. In a recent study, Contreras et al. ${ }^{19}$ examined the fit of cast CPTi and Ti6Al4V alloy crowns. They found the marginal fit of Ti6Al4V alloy crowns $(50.8 \mu \mathrm{m})$ was significantly better than CPTi $(83.9 \mu \mathrm{m})$.

The authors are unaware of any reports related to the marginal fit of CPTi or Ti6Al4V alloy FPD retainers available in the literature. The low density of Ti may reduce the mold-filling ability (castability) and might result in incomplete margins. ${ }^{3}$ Titanium has a high chemical reactivity at elevated temperatures. As a result, the casting technique requires special melting procedures and investment materials, careful cooling cycles, and an expensive casting machine in order to achieve a proper casting and to avoid metal contamination. ${ }^{1}$ The purpose of this study was to investigate the marginal accuracy and internal fit of complete crowns and three-unit FPD castings fabricated from CPTi and Ti6Al4V alloy.

\section{Methods and Materials}

A previously reported, a three-piece aluminum mold to prepare testing specimens was used after some modification. ${ }^{20,21}$ The mold accommodated three stainless steel dies and one blank attached to the mold base. The first die represented a first molar preparation. The remaining two dies and one blank represented a three-unit FPD consisting of a second premolar die, a first molar pontic, and a second molar die (Figure 1).

The dies represented a complete crown preparation of $5.8 \mathrm{~mm}$ height with a five-degree axial wall taper and a $1 \mathrm{~mm}$ shoulder. The gingival diameter was $5.9 \mathrm{~mm}$ for the premolar and 7.5 $\mathrm{mm}$ for the molars. The occlusal surface of each die had an offset v-shaped cross groove to serve as an anti-rotational index. Dies were individually removable, indexed to the mold base, and locked with Allen-head screws. A guide pin on each end of the mold base (Block 1, Figure 1) was designed to extend through designated holes on each end of Block 2 to facilitate and insure fitness of Block 2 of the mold onto Block 1. The midsection (Block 2) consisted of two split halves. It fits around the finish line of each die or blank and has a five-degree outward taper from the gingival margin to the superior edge of the block leveled with the base of the connector area of the FPD. Two metal clips were laid over the midsection to firmly hold it to the

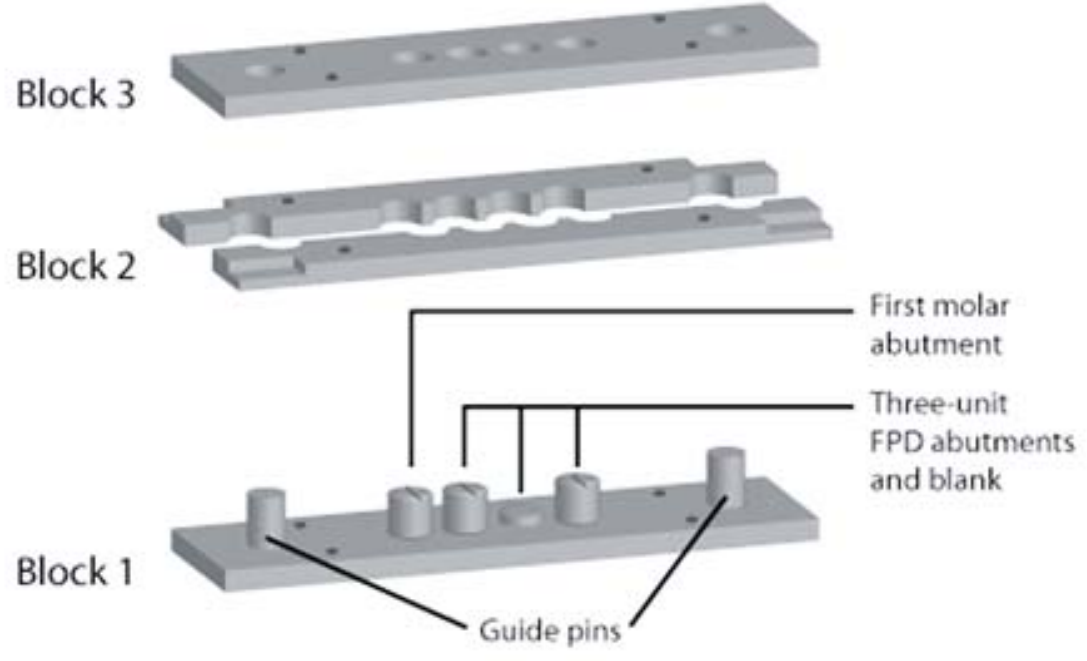

Figure 1. Schematic drawing of the aluminum mold. 
Table 1. Description of the metals and their chemical composition.

\begin{tabular}{|l|l|l|l|l|}
\hline \multicolumn{1}{|c|}{ Alloy type } & \multicolumn{1}{|c|}{$\begin{array}{c}\text { Product } \\
\text { name }\end{array}$} & \multicolumn{1}{|c|}{ Manufacturer } & \multicolumn{1}{c|}{ Composition* } & \multicolumn{1}{c|}{ Code } \\
\hline $\begin{array}{l}\text { Commercially } \\
\text { pure } \mathrm{Ti}\end{array}$ & Tritan & $\begin{array}{l}\text { Dentaurum, Ispringen, } \\
\text { Germany }\end{array}$ & $\begin{array}{l}>99.5 \% \mathrm{Ti}, 0.03 \% \mathrm{~N}, 0.1 \% \mathrm{C}, 0.015 \% \mathrm{H}, \\
0.30 \% \mathrm{Fe}, 0.25 \% \mathrm{O}\end{array}$ & $\mathrm{CPTi}$ \\
\hline $\mathrm{Ti}$ alloy & Ti6Al4V & $\begin{array}{l}\text { VSMPO, Verkhnaya } \\
\text { Salda, Russia }\end{array}$ & $\begin{array}{l}>89 \% \mathrm{Ti}, 6.5 \% \mathrm{Al}, 4.2 \% \mathrm{~V}, 0.01 \mathrm{C}, 0.17 \% \mathrm{Fe}, \\
<0.0005 \% \mathrm{Y}, 0.178 \% \mathrm{O}, 0.008 \% \mathrm{~N}, 0.0003 \% \mathrm{H}\end{array}$ & $\mathrm{Ti}-6 \mathrm{Al}-4 \mathrm{~V}$ \\
\hline
\end{tabular}

* provided by the manufacturers.

mold base (Block 1, Figure 1). The top section of the mold (Block 3, Figure 1) forms the upper portions of the retainers, pontics, and connectors. This portion of the mold had a five-degree inward taper from the base of the connector to the occlusal surface and has four guide pins that fit in designated holes in the midsection to insure maximum stabilization during the waxing procedure. Openings on the top section, opposite to each die, were prepared to facilitate pouring of the molten wax. The connector area was $2 \mathrm{~mm} x$ $2 \mathrm{~mm} \times 1 \mathrm{~mm}$ in dimension.

The materials used in this study were Grade 1 CPTi (Tritan, Dentaurum, Ispringen, Germany) and Ti-6Al-4V alloy (Vsmpo, Parkovaya St., Verkhnaya Salda, Sverdlovsk reg., Russia). Table 1 shows the specifications and chemical compositions of the metals. Twenty-four specimens were prepared; half of them were cast in CPTi (six single crowns and six three-unit FPDs) and the remaining were cast in Ti-6Al-4V alloy (six single crowns and six three-unit FPDs).

Prior to the waxing procedure, three coats of die spacer (True-Fit. Geo Taub, Jersey City, NJ, USA), were applied to each die while being kept within $1 \mathrm{~mm}$ of all margins. Then the dies were lightly lubricated with a die separating agent (Die Lube, Dentaurum, Ispringen, Germany) followed by securing the three sections of the mold to each other. Inlay wax (BioWax, Dentsply, York, PA, USA) was warmed for five minutes at $50^{\circ} \mathrm{C}$ in a furnace along with the die assembly. The wax was poured into the mold through the openings in the top section.

The mold was kept at room temperature $\left(23^{\circ} \mathrm{C}\right)$ for one minute then the mold was separated and the wax pattern was retrieved. Remargination was carried out by adding warmed inlay wax around the retainers and crown margins. Excess wax was carefully removed by using PKT
(Thomas) No. 4 instrument, and the accuracy of margins was checked by using a Stereo 80 widefield microscope (Swift Instruments International, Tokyo, Japan). The patterns were sprued and invested using a silica-free and phosphatefree, alumina and magnesia-based investment (Rematitan Ultra) according to the manufacturer's instructions. A Ti casting machine (Castmatic, Dentaurum, Ispringen, Germany) was used to cast the specimens and cleaned following manufacturer's instructions to avoid contamination during the casting procedure.

Metal nodules in the fitting surface were removed with a mini and midi Ti hard metal bur (Dentaurum, Ispringen, Germany) under a Stereo 80 widefield microscope (Swift Instruments International, Tokyo Japan). Fit-checker (Ghm-Spray, Hanel, Langenau, Germany) was sprayed in the internal side of each casting which was then seated with finger pressure. The binding areas were removed with a midi bur (Dentaurum). This procedure was repeated five times for each casting. Pressure spot indicator (Coltene PSI, Coltene, Altstatten, Switzerland) was mixed according to manufacturer instructions and then applied to the internal surface of the casting. Each casting was seated over its corresponding die with finger pressure and held until the pressure indicator set. Binding areas were marked by pencil and removed with the midi bur. This procedure was repeated two times (Figure 2). Specimens' preparation and fitting procedures were achieved by one investigator.

A traveling microscope (TM 10 Measuring Microscope, Titan, Buffalo, NY, USA) with micro calibrations was used to measure the marginal and internal discrepancies. The accuracy of the microscope was tested using a steel plate with a known thickness of $730 \mu \mathrm{m}$ as measured with a digital micrometer (Fowler, Fred Fowler Co. Inc., Newton, MA, USA). 


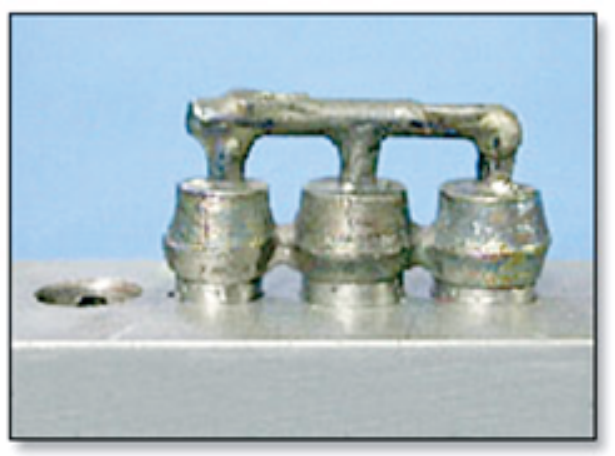

Figure 2. A three-unit FPD placed over its corresponding dies and ready for measurement.

\section{Marginal Gap Measurement}

The vertical marginal discrepancies between the margin of the casting and the external line angel of the shoulder of the metal die were measured. Four measuring sites with equal distances away from each other were selected on the metal dies to represent the mid-buccal, mid-lingual, mid-distal, and mid-mesial aspects of the dies. Measurements were repeated three times for each site. Each set of measurements were carried out in a different session. The mean of the four site measurements was obtained for each crown/retainer and was considered to be the gap measurement.

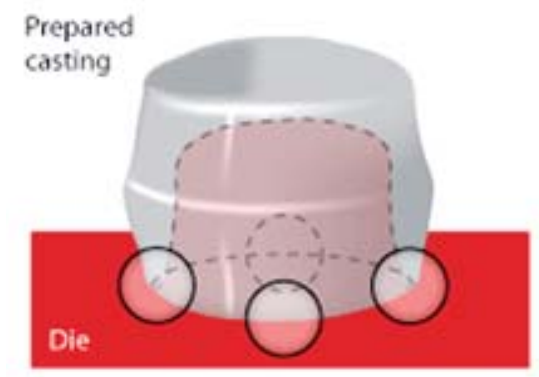

Marginal Gap Measurement Sites

\section{Internal Fit Evaluation}

To evaluate the internal fit discrepancy each specimen was individually embedded in auto polymerizing acrylic resin and sectioned faciolingually through the long axis of the single crown or retainer using a precision saw (Isomet 200, Buehler, Ltd., Lake Bluff, IL, USA) (Figure 3).

Half of the sectioned specimen was seated on the metal die for measurements. The internal gaps were measured halfway through the buccal and lingual walls occlusogingivally and halfway through the occlusal table faciolingually under the

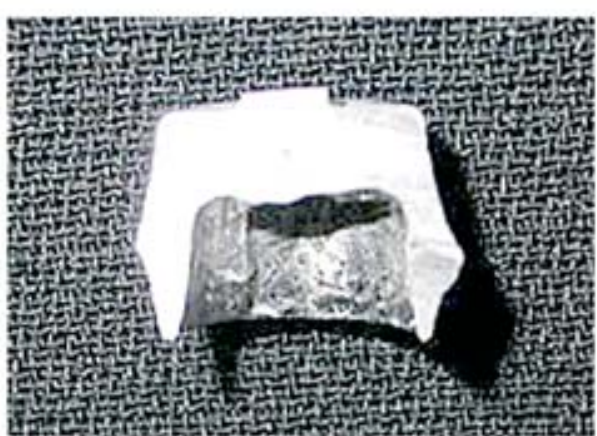

Figure 3. A sectioned crown specimen.

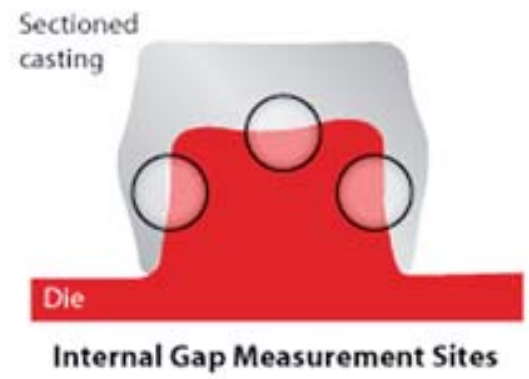

traveling microscope at three sites for each specimen. Measurements were repeated three times for each site. The mean of these three measurements was obtained. All the measurements were taken by one investigator.

Statistical software (SPSS for Windows, Release 11.0.0, 2001, SPSS Inc) was used to generate descriptive statistics and perform inferential tests. The analysis of variance (ANOVA) was conducted to determine the effect of the two factors (metals and restorations) and their interactions. The paired t-test and the Pearson correlation were used to examine the intra-examiner reliability.

\section{Results}

A high level of intra-examiner reliability was demonstrated by using the paired t-test and the Pearson correlation. The paired t-test showed the difference was not significant $(P=0.831)$. The Pearson correlation was $95.3 \%$.

\section{Vertical Marginal Discrepancies}

The grand mean and standard deviation values for vertical marginal discrepancies for the single crown and FPD retainers are summarized in Table 2. The lowest mean marginal gap was recorded for the single crown of Ti-6Al-4V (36.87 $\mu \mathrm{m})$, whereas the highest was recorded for the premolar retainer of the FPD of CPTi $(83.36 \mu \mathrm{m})$. 
Table 2. Mean vertical marginal gaps and standard deviations ( \pm SD) in $\mu \mathrm{m}$.

\begin{tabular}{|l|c|c|}
\hline \multicolumn{1}{|c|}{ Restoration } & CPTI & TI-6Al-4V \\
\hline SC & 42.05 & 36.87 \\
& $( \pm 3.77)$ & $( \pm 3.15)$ \\
\hline FPD & 83.36 & 67.31 \\
(premolar) & $( \pm 3.90)$ & $( \pm 3.71)$ \\
\hline FPD & 61.56 & 54.05 \\
(molar) & $( \pm 2.86)$ & $( \pm 3.60)$ \\
\hline
\end{tabular}

Abbreviations: $\mathrm{SC}=$ single crown; FPD=fixed partial denture

Table 3. Mean internal fit and standard deviations ( \pm SD) in $\mu \mathrm{m}$.

\begin{tabular}{|l|c|c|c|c|c|c|}
\hline \multirow{2}{*}{ Restoration } & \multicolumn{3}{|c|}{ CPTI } & \multicolumn{3}{c|}{ TI-6Al-4V } \\
\cline { 2 - 8 } & Mid-buccal & Mid-occlusal & Mid-lingual & Mid-buccal & Mid-occlusal & Mid-lingual \\
\hline SC & 51.22 & 101.18 & 47.41 & 40.64 & 91.30 & 38.24 \\
& $( \pm 2.55)$ & $( \pm 4.32)$ & $( \pm 3.08)$ & $( \pm 3.20)$ & $( \pm 4.35)$ & $( \pm 4.35)$ \\
\hline FPD & 43.60 & 119.80 & 41.06 & 35.84 & 101.60 & 33.16 \\
Premolar & $( \pm 3.49)$ & $( \pm 4.71)$ & $( \pm 3.17)$ & $( \pm 2.69)$ & $( \pm 4.54)$ & $( \pm 2.35)$ \\
\hline FPD & 33.16 & 101.74 & 30.48 & 27.80 & 98.78 & 27.80 \\
Molar & $( \pm 2.36)$ & $( \pm 4.83)$ & $( \pm 3.07)$ & $( \pm 3.35)$ & $( \pm 4.16)$ & $( \pm 2.83)$ \\
\hline
\end{tabular}

Two-way ANOVA revealed a statistical significant effect between type of metal $(P<0.001)$ and restoration $(P<0.001)$. Furthermore, a statistical interaction effect between type of metal and restoration was found $(P<0.001)$. Since there were interaction effects, a one-way ANOVA was then performed. It revealed Ti-6Al-4V showed significantly better vertical marginal fit than CPTi, which was true for both types of restorations $(P<0.004)$. In addition, single crowns had a better vertical marginal fit than FPD retainers. This was true for both metals used $(P<0.001)$.

\section{Internal Discrepancies}

The means and the standard deviation values for the internal fit for the single crown and FPD retainers are depicted in Table 3 . The highest gap between the casting and the metal die was recorded at the mid-occlusal point of the premolar for both CPTi $(119.80 \mu \mathrm{m})$ and Ti-6AI-4V (101.60 $\mu \mathrm{m})$. When the two metals were compared, the two-way ANOVA showed significant differences between metals $(P<0.001)$. The one-way ANOVA showed Ti-6Al-4V revealed significantly smaller internal gaps than CPTi which was true for both types of restorations $(P<0.001)$. The internal fit at mid-occlusal site was significantly greater than the axial fit which is true for both the CPTi and Ti-6Al-4V and for both restorations $(\mathrm{P}<0.001)$.

\section{Discussion}

The fit of cast restorations made with $\mathrm{CPTi}$ and Ti-6Al-4V were investigated under controlled experimental conditions by measuring the marginal and internal fit discrepancies of the single crown and three-unit FPD castings. The three-piece mold used in this study was modified from the three-piece mold documented in previous studies. ${ }^{20,21}$ The modification was done in Block 2 which consisted of two split halves secured to Block 1 by two metal clips. This modified design minimized the wax distortion during disassembling of the device for retrieving the wax pattern. The lubricated die assembly was warmed in a $50^{\circ} \mathrm{C}$ oven for five minutes before waxing. This warming process was designed to reduce the internal stresses within the pattern. Reduction of the internal stresses decreases the amount of wax distortion during subsequent handling of the wax pattern.

The Ti-6Al-4V specimens demonstrated better marginal and internal fit discrepancies than CPTi specimens of all tested groups. This is in concurrence with Contreras et al. ${ }^{19}$ This can attributed to the improved castability of the Ti-6Al-4V which could be attributed to the differences in melting temperature, thermal expansion coefficient, and density. ${ }^{19}$ 
The results of the present study showed the mean marginal gaps for single crown castings were $42 \mu \mathrm{m}$ for the CPTi group and $36.8 \mu \mathrm{m}$ for the Ti-6Al-4V alloy group. This was smaller than the values reported by previous studies for cast ${ }^{14,17-19}$ or machine-milled ${ }^{17,22,23} \mathrm{Ti}$ crowns. In addition, the internal discrepancy found in this study for single crown castings was smaller than the values reported by Boening et al. ${ }^{22}$ and Valderrama et al. ${ }^{23}$ for machine-milled $\mathrm{Ti}$ crowns. This improvement in marginal gaps in the present study might be due to the use of different investment material with manufacturer claims of a better fit than previously introduced investments. There were no published studies evaluating this new investment. Furthermore, this improvement could be attributed to the direct technique of waxing employed in the present study and fitchecking methodology.

The internal discrepancy results for the single crown and the three-unit FPD castings showed the gaps between the restorations and their corresponding dies were greater at mid-occlusal sites than at axial sites. This confirmed the findings of Valderrama et al ${ }^{23}$ for machine-milled $\mathrm{Ti}$ crowns and Marker et al. ${ }^{24}$ for gold alloy crowns. The most plausible explanation for the difference in the internal discrepancy between occlusal and axial areas is the expansion behavior of the investment material in the casting ring. During setting expansion, the axial surfaces are substantially restricted by the walls of the metal investment ring. Whereas the occlusal surface is unrestricted since it was oriented toward an open end of the investment ring. Moreover, thermal expansion of the investment may further allow the occlusal surface to expand more during wax elimination consequently increasing the occlusal internal gap.

Schiffleger et al. ${ }^{20}$ investigated the accuracy of different lengths of FPDs cast in a gold-palladium alloy using a similar mold. For a three-unit FPD, they reported $76 \mu \mathrm{m}$ mean vertical marginal gap for the premolar retainer and $32 \mu \mathrm{m}$ for the molar retainer. These values are smaller than the values reported by the present study even though they did not attempt to do any fit-checking procedures. This indicates CPTi and Ti-6Al-4V still have an inferior marginal fit compared with gold-based alloys which was reported by several previous studies. ${ }^{17,23,25}$

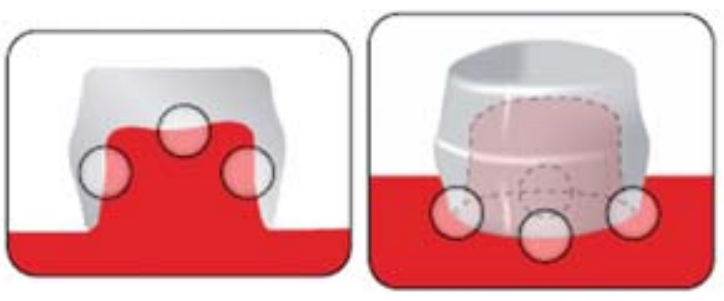

Inadequate adaptation of cast restoration may be detrimental to both the tooth and supporting periodontium. Previous investigations have reported acceptable marginal gap values ranging from 50 to $114 \mu \mathrm{m} .{ }^{11-14}$ However, several authors agree a marginal gap less than $100 \mu \mathrm{m}$ appears to be within the range of what is clinically acceptable for the longevity of restorations. ${ }^{11-13,17,19}$ If the 100 $\mu \mathrm{m}$ were used as a boarder line, all the readings will lie within the acceptable range. However, from both biologic and mechanical perspectives, passive fit between dental implants and prosthetic superstructures has been recognized as a potential discriminating prognostic factor.

One of the limitations of this investigation was the lack of cementation of the castings prior to the internal fit measurements since minor movement might affect the readings. However, the metal die's $1 \mathrm{~mm}$ shoulder and the occlusal v-shaped groove should decrease the possibility of such movements. The application ceramic material may further affect the casting fit. Therefore, evaluating the marginal fit of CPTi and Ti-6Al-4V before and after ceramic application seems advisable for a future study.

The opaque substructure of the metal-ceramic restoration restricts its potential in the area of high esthetic importance. Therefore, the trend today is toward fabricating all-ceramic restorations since contemporary all-ceramic systems offer a new esthetic dimension.

\section{Conclusions}

Within the limitations of this investigation, the following conclusions were made:

1. Ti-6Al-4V demonstrated less fit discrepancy than CPTi; however, both castings were clinically acceptable.

2. Single crowns showed better fit than the three-unit FPD. This was true for both CPTi and Ti-6Al-4V.

3. Mid occlusal internal fit demonstrated greater gap discrepancy than the axial internal fit. 


\section{References}

1. Wang RR, Fenton A. Titanium for prosthetic application: a review of the literature. Quintessence Int 1996;27:401-8.

2. Andersson $M$, Bergman $B$, Bessing $C$, Ericson $G$, Lundquist $P$, Nilson $H$. Clinical results with titanium crowns fabricated with machine duplication and spark erosion. Acta Odontol Scand 1989;47: 279-286.

3. Akagi K, Okamoto Y, Matsuura T, Horibe T. Properties of test metal ceramic titanium alloys. J Prosthet Dent 1992;68:462-7.

4. Carr AB, Brantley WA. Titanium alloy cylinders in implant framework fabrication: A study of the cylinder-alloy interface. J Prosthet Dent 1993;69:391-7.

5. Kononen M, Kivilahti J. Fusing of Dental Ceramics to Titanium. J Dent Res 2001;80:848-54.

6. Ohkubo C, Shimura I, Aoki T, Hanatani S, Hosoi T, Okabe T. In vitro wear assessment of titanium alloy teeth. J Prosthodont 2002;11:263-9.

7. Rodrigues RC, Ribeiro RF, de Mattos Mda G, Bezzon OL. Comparative study of circumferential clasp retention force for titanium and cobalt-chromium removable partial dentures. J Prosthet Dent 2002;88:290-6.

8. Lautenschlager EP, Monaghan P. Titanium and titanium alloys as dental materials. Int Dent $\mathrm{J}$ 1993;43:245-53.

9. Taira M, Moser JB, Greener EH. Studies of Ti alloys for dental castings. Dent Mater 1989;5:45-50.

10. Oda Y, Okabe T. Effect of corrosion on the strength of soldered titanium and Ti-6Al-4V alloy. Dent Mater 1996;12:167-72.

11. Dedmon HW. Disparity in expert opinions on size of acceptable margin openings. Oper Dent 1982;7:97-101.

12. McLean JW, Von Fraunhofer JA. The estimation of cement film thickness by an in vivo technique. Br Dent J 1971;131:107-11.

13. Kashani HG, Khera SC, Gulker IA. The effects of bevel angulation on marginal integrity. J Am Dent Assoc 1981;103:882-5.

14. Blackman R, Baez R, Barghi N. Marginal accuracy and geometry of cast titanium copings. J Prosth Dent 1992;67:435-40.

15. Baez R, Blackman R, Barghi N, Tseng E. Marginal fit of pure titanium cast crown copings. J Dent Res 1989;68:269.

16. Ida K, Tani Y, Tsutsumi S, Togaya T, Nambu T, Suese K, Kawazoe T, Nakamura M, Wada H. Clinical application of pure titanium crowns. Dent Mater J 1985;4:191-5.

17. Leong D, Chai J, Lautenschlager E, Gilbert J. Marginal Fit of Machine-Milled Titanium and Cast Titanium Single Crowns. Int J Prosthodont 1994;7:440-7.

18. Oruc S, Tulunoglu Y. Fit of titanium and a base metal alloy metal-ceramic crown. J Prosthet Dent 2000;83:314-8.

19. Contreras EF, Henriques GE, Giolo SR, Nobilo MA. Fit of cast commercially pure titanium and Ti$6 \mathrm{Al}-4 \mathrm{~V}$ alloy crowns before and after marginal refinement by electrical discharge machining. J Prosthet Dent 2002;88:467-72.

20. Schiffleger BE, Ziebert GJ, Dhuru VB, Brantley WA, Sigaroudi K. Comparison of accuracy of multiunit one-piece castings. J Prosthet Dent 1985;54:770-6.

21. Ziebert GJ, Hurtado A, Glapa C, Schiffleger BE. Accuracy of one-piece castings, preceramic and post ceramic soldering. J Prosthet Dent. 1986; 55:312-17.

22. Boening KW, Walter MH, Reppel PD. Non-cast titanium restorations in fixed prosthodontics. J Oral Rehabil 1992;19:281-7.

23. Valderrama S, Van Roekel N, Andersson M, Goodacre CJ, Munoz CA. A comparison of the marginal and internal adaptation of titanium and gold-platinum-palladium metal ceramic crowns. Int $\mathrm{J}$ Prosthodont 1995;8:29-37.

24. Marker VA, Miller AW, Miller BH, Swepston JH. Factors affecting the retention and fit of gold castings. J Prosthet Dent 1987;57:425-30.

25. Stoll R, Markris P, Stachniss V. Marginal adaptation of cast partial crowns made of pure titanium and a gold alloy under influence of a manual burnishing technique. J Oral Rehabil 2001;28:401-6. 
About the Authors
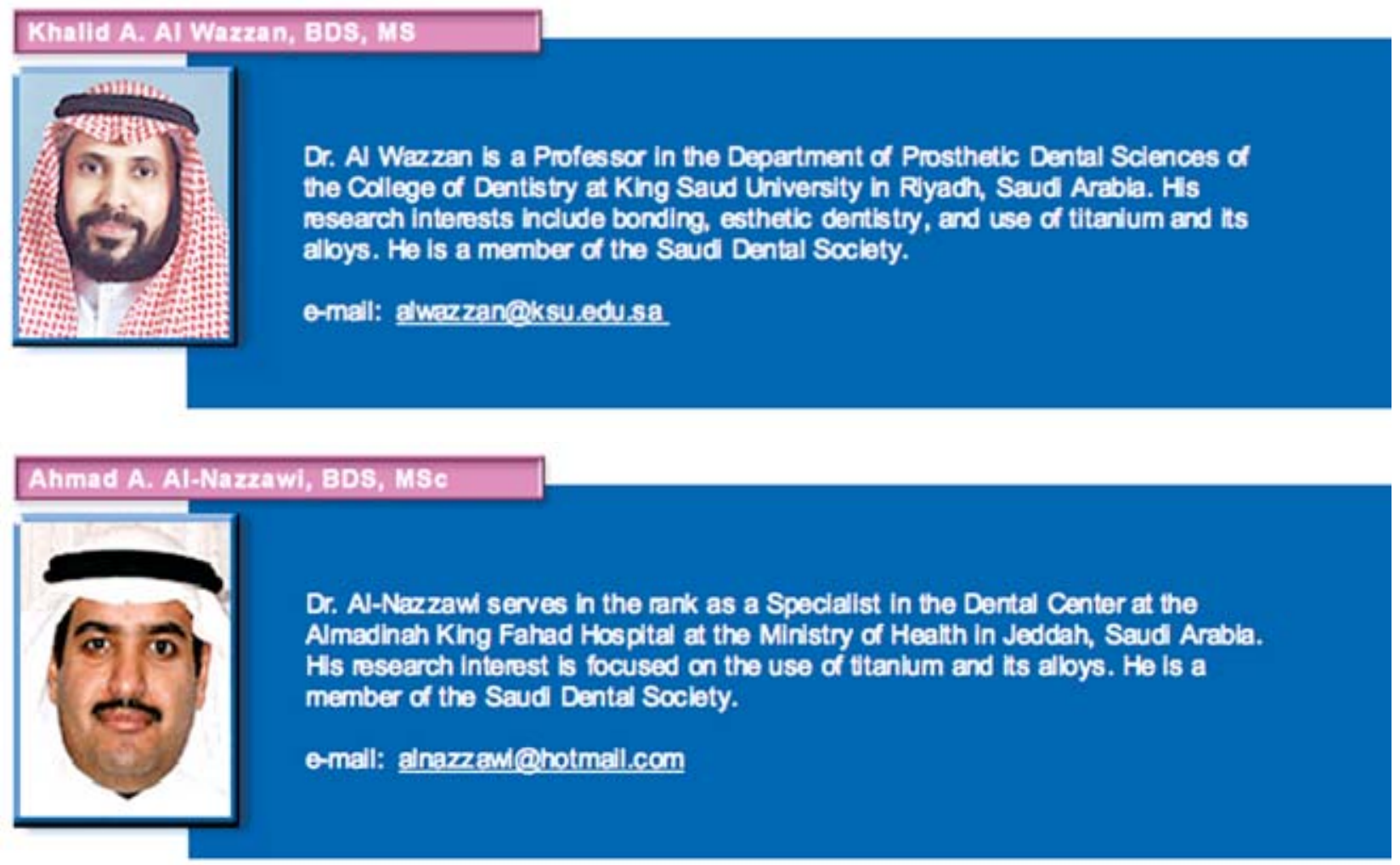